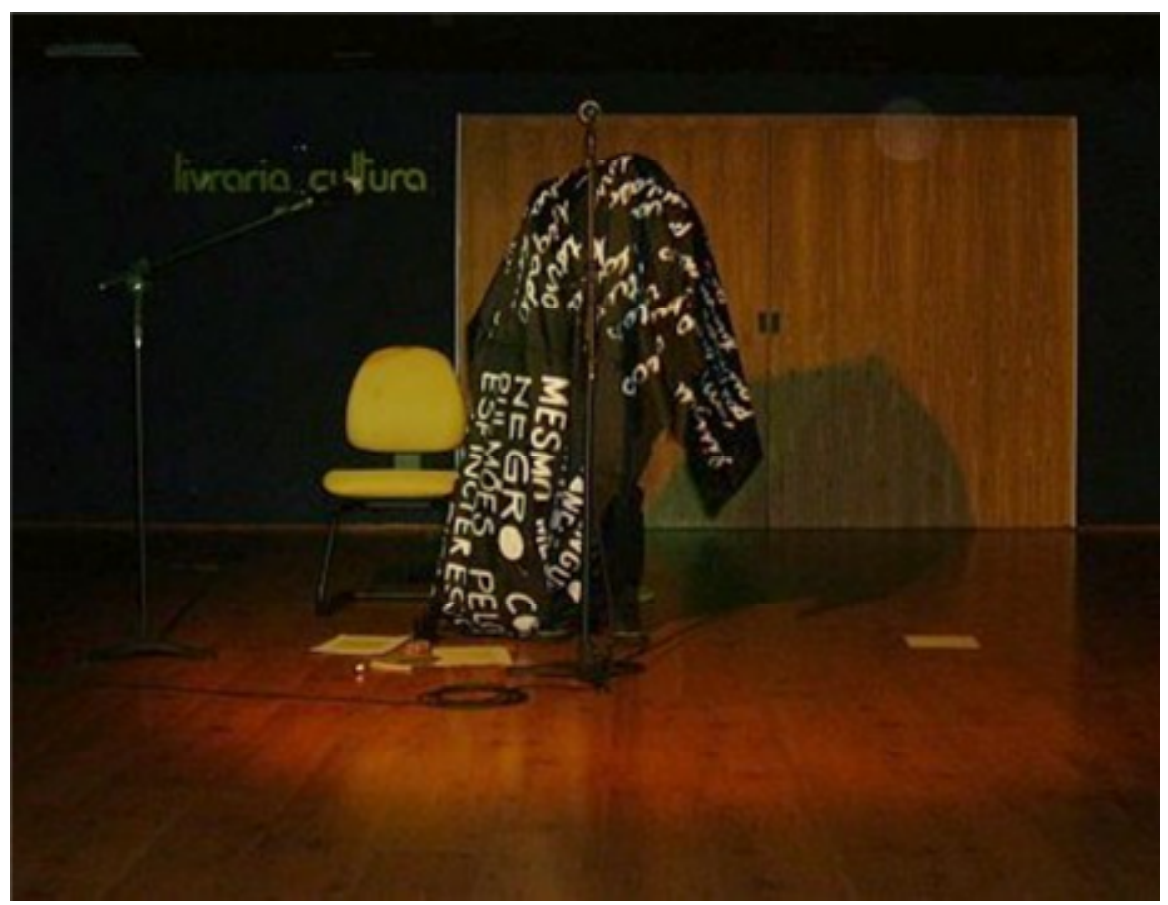

Ricardo Aleixo em performance

\title{
A desconstrução do cânone na poesia
}

\section{Ricardo Aleixo \\ por Conceição Bicalho e Fabiana Fernandes}

Ricardo Aleixo é poeta, músico, artista visual e ensaísta. Publicou, entre outros, os livros Trívio (2001) e Máquina Zero (2004). Tem, no prelo, o livro de ensaios Palavras a olhos vendo - Escritos sobre escritas. É curador do FAN-Festival de Arte Negra e da ZIP-Zona de Invenção Poesia \&. Integra e performer do Combo de Artes Afins Bananeira-ciência e a Cia. SeráQuê?.

Conceição Bicalho é Mestre em Artes Visuais pela Escola de Belas Artes da UFMG. Artista plástica, ilustradora e professora de Ilustração no Departamento de Desenho da EBA desde 2003. Foi professora de Xilogravura, Desenho e Cerâmica na UEMG no período de 1998 a 2002.

Fabiana Fernandes é graduanda do curso de letras da FALE UFMG, aluna de Iniciação Científica e coordenadora do site do Programa A tela e o texto. 
Conceição Bicalho e Fabiana Fernandes - Como é seu processo criativo? Se você viesse a trabalhar na área de educação, onde método e pesquisa direcionam um saber, você estabeleceria a partir de sua experiência a formação de artistas na criação de algum cânone, por exemplo o "cânone da Internet" ?

Ricardo Aleixo - Meu processo criativo não se fecha, felizmente, num único modus operandi. Como digo no poema Máquina Zero, do livro homônimo, sinto-me "permeável a tudo", - que, se por um lado me abre mais a percepção do mundo, por outro me obriga a escolher o que criar, a definir o por quê e de que modo fazê-lo. Método e pesquisa não constituem em problemas para mim. Venho de uma linhagem artística para a qual o pensamento é inerente à obra, não há cisão entre uma coisa e outra. A "coisa feita" é sempre plena de pensamento. A coisa se faz como um pensamento. Digo o mesmo quanto à pesquisa sistemática. Na minha vida de autodidata, aquilo do que mais sinto falta é da possibilidade de compartilhamento programático, não episódico - no decorrer das pesquisas. A solidão, ao mesmo tempo que é necessária para fazer aflorar a contemplação, sem a qual não surgirá a teoria, torna-se algo penoso, já que nos impede de ter contato com a visão - a teoria - do outro, ainda na fase do processo de busca.

Quanto à hipótese de trabalhar na área de educação, vejo isso como um possível desdobramento de experiências que venho tendo, de uns anos para cá, como professor em oficinas, cursos livres e mesmo em cursos de pós-graduação. Me sinto muito gratificado com a experiência em sala de aula, embora não alimente qualquer desejo nesse sentido. Vontade grande, tenho mesmo é de coordenar projetos de pesquisa no âmbito de alguma instituição. Agora, com relação a estabelecer um cânone, digo com total tranqüilidade que nada tenho a ver com isso. Minha formação de base anarquista me leva bem mais a pretender destruir o cânone, qualquer que seja sua orientação. Internet, de resto, é ferramenta, não um gênero artístico, não é? Um "cânone da Internet" talvez tenha que lidar mais com objetos não pensados com intenções "artísticas", e menos com "arte", no sentido que tradicionalmente se atribui a essa palavra. Mas não deixa de ter seu interesse a idéia: um cânone feito e refeito continuamente, com a contribuição inclusive de pessoas para as quais a idéia de cânone soaria como grego arcaico.

Paradoxalmente você defende a poesia oral e atribui ao livro um papel de suporte do texto. Sua investida na arte gráfica se deu por meio de leituras de textos (e conseqüentes diagramações) ou você acredita que $\circ$ poema exige a 
Não vejo qualquer paradoxo nisso. Proponho a oralidade, ou melhor, a vocalidade, como um elemento composicional tão importante, na confecção do poema, quanto as palavras, os silêncios e tudo o mais. Voz como, ela própria, um dispositivo tecnológico compreende? Não há, no meu projeto criativo, dicotomia entre a voz e a letra, para retomar aqui o título de uma obra fundante de Paul Zumthor. Ambas são, na melhor das hipóteses, complementares. Comecei a me interessar por artes gráficas, influência direta de Sebastião Nunes. Eu, que na infância, muito antes de me interessar por poesia, já curtia estruturas gráfico-visuais - como as das revistas e jornais, placas de rua e outdoors e tal -, me vi totalmente arrebatado pela obra do Tião. Lá pelos vinte anos de idade, ingênuo como só um garoto sonhador pode ser, encontrei meu ídolo na avenida Augusto de Lima e, de cara, pedi que ele lesse meus experimentos. Ele: "Pra quê?". Eu: "Bom, queria saber sua opinião, como poeta e editor". Ele: "Só edito a minha própria poesia e a dos meus amigos". Eu (já com o rabo entre as pernas): "Valeu pela atenção. Obrigado". Conto essa história porque ela me obrigou, para não ceder ao impulso de entrar no primeiro bueiro que me aparecesse pela frente, a formular um projeto de vida e criação mais consistente. Não fiquei magoado com o Tião, que anos depois se tornaria meu amigo e parceiro de criação. Pelo contrário. Fui estudar por conta própria. Comprei tanto livros teóricos sobre design gráfico e programação visual quanto catálogos de tipos, manuais de desenho de fontes etc. Até hoje, busco me manter informado sobre $O$ que há de novo nesse campo - sem me descuidar do passado, esse poço sem fundo. Ah! Não se deve esquecer que poema é forma.

\section{A partir de que fato ou data você incluiu a performance como necessária aos seus poemas? Você cria poesias da mesma forma que happenings?}

Ao contrário do que se pensa, meu primeiro contato com a arte se deu por meio da música, por volta dos 11 anos. Depois, lá pelos 14, passei um tempo grande voltado para as artes visuais, sem deixar de lado a música - e já jogando futebol, que foi minha grande paixão até os 18 anos, quando recebi uma bolada no olho direito que me impediu de continuar a jogar. Olhe só para o lugar de onde vem a sugestão para o trabalho com performance, com o corpo em relação com o espaço: do futebol, e não das artes (meu amigo zé Miguel Wisnik diz, e eu concordo, que o futebol contém aquilo que nas artes ainda é projeto). Quando, aos 14 anos, eu começo a escrever poemas, 
eles já surgem, ainda que incipientes, com essa vontade de saltar da página para outros ambientes: para a tela, para o objeto tridimensional, para a cena. Meus espetáculos e performances, em síntese, são apenas tentativas de reconfigurar tudo, todos esses dados, num mesmo ambiente. O cinema para você é tema de poesia ou você sonha a poesia
visual?

As duas respostas são válidas. Há um tipo de visualidade, no meu projeto, que passa pela imaginação, pela tentativa de reter imagens não existentes no plano da materialidade sígnica. E há uma terceira via: quero do cinema sua infraestrutura, o que possa haver de mais específico nele enquanto arte. Não quero dele os temas ou seus cacoetes, mas sua capacidade de operar junções qualitativas (som + imagem em movimento + palavra transformada em imagem + tensionamento dos elementos $+\ldots$...).

\section{Como você explica seu acesso aos principais centros de cultura internacionais, mesmo tendo uma postura crítica e por vezes radical em relação ao mercado da arte?}

O mercado artístico-cultural é voraz e novidadeiro, o que pode explicar, de certa forma, o pequeno interesse que meu trabalho começa a despertar dentro e fora do país. Digo "pequeno" sem qualquer modéstia. Ter ido a alguns países europeus, ter tido poemas publicados em lugares como Estados Unidos, França, País de Gales etc. me enche de vaidade, claro, mas não traz muitos outros ganhos. Pode ser que traga, na medida em que eu passe a me organizar para ter uma carreira internacional. Carreira, não sei, mas venho pensando em passar algum tempo fora, estudando, fazendo contatos, visitando centros de pesquisa e produção. De todo modo, tenho comigo que é no campo da performance intermídia - com ênfase no uso da oralidade midiatizada e da imagem - que posso ter alguma chance. Recentemente, inclusive, a revista Lápiz, da Espanha, publicou uma longa reportagem sobre arte sonora - que não se reduz à poesia sonora, envolvendo também a música experimental e a radioarte - no Brasil em que fui citado com destaque.

\section{Você pensa um outro momento de efervescência da arte (talvez menos rico em mídias como hoje) que você gostaria de revisitar para retomar questões esquecidas?}

O grande Paulinho da Viola, que não canso de citar, tem aquela ótima frase, que serviu de título para um bonito documentário feito sobre sua obra: "Meu tempo é hoje". Não sou nostálgico. 
Além do mais, minha condição de sujeito contemporâneo permite que eu seja "de todos os tempos sem deixar de ser do agora", como resumiu lindamente Octavio Paz, no seu conhecido ensaio sobre Marcel Duchamp. Não sou desses que cultivam a frágil idéia de progresso em arte. A única vantagem do nosso tempo sobre os demais é que nós podemos pensar as obras produzidas no passado sem a mediação - por vezes intimidadora - dos que as criaram. De resto, não creio na existência de "questões esquecidas" na arte. Se tal "esquecimento" ocorreu, alguma razão há de ter havido. Da mesma forma, por algum motivo imprevisto, pode ocorrer uma nova irrupção dessas questões, em clave contemporânea. Dá-se a isso o nome de perspectiva sincrônica: as perguntas ainda não devidamente respondidas voltarão, sempre, a ocupar seu espaço no mundo real e no mundo dos signos. O difícil é saber, à maneira de Gertrude stein, como distinguir "Qual é a resposta? Qual é a pergunta?".

\section{Como é seu processo na criação musical? Mais uma vez é a poesia direcionando sua criação? Fale-nos mais sobre a sua música no seu trabalho.}

Embora tenha me iniciado nas artes, como já disse, fazendo música, posso dizer que hoje faço música no "sentido lato", no sentido que Hélio Oiticica atribuía ao seu próprio trabalho: "O q faço é música". Meu pensamento é, mais que literário, musical. E poesia, como já nos ensinara o velho Ezra Pound, não é bem literatura, estando bem mais próxima da música e das artes visuais. Claro, também faço canções - sozinho ou com parceiros como Maurício Tizumba, Juarez Maciel, Gilvan de Oliveira, Gil Amâncio, Kristoff Silva, Zeca Baleiro -, mas não tenho qualquer plano no sentido de dar sequiência a uma carreira estritamente musical. Não falo "musiquês" o suficiente para encarar o convívio com os "xiitas da música"...

\section{- que é ganho e o que é perda para a poesia com a alta divulgação e vulgarização da cultura a partir da Internet?}

Está tudo em aberto, para o bem e para o mal. Só nos cabe esperar. A Internet relativiza a questão da escala. O poema fraquinho de um jovem blogueiro fica a um "click" de distância da reprodução de uma iluminura de William Blake. Ou do site do Nam June Paik. Ou da animação digital de um poema concreto. Ou do desabafo em forma de versos da mulher abandonada pelo amante. Ou dos experimentos sonoros de um Stockhausen. Precisa é saber escolher, já que as ofertas aumentaram sensivelmente. Agora é com cada um. 